\title{
The Seasonal Difference in Soil Moisture Patterns Considering the Meteorological Variables Throughout the Korean Peninsula
}

\author{
Eunsang $\mathrm{Cho}^{1}$, Aoqi Zhang ${ }^{2}$, and Minha Choi ${ }^{3, *}$ \\ ${ }^{I}$ Department of Civil and Environmental Engineering, University of New Hampshire, Durham, New Hampshire, U.S.A. \\ ${ }^{2}$ Department of Civil \& Environmental System Engineering, Sungkyunkwan University, Suwon, Republic of Korea \\ ${ }^{3}$ Department of Water Resources, Graduate School of Water Resources, Sungkyunkwan University, Suwon, Republic of Korea
}

Received 8 March 2016, revised 11 July 2016, accepted 12 July 2016

\begin{abstract}
This study focuses on the seasonal differences in soil moisture patterns considering the impact of meteorological variables (air/ground temperature, precipitation, and the amount of insolation) on soil moisture variability over the Korean peninsula between January 2012 and February 2013. We found that soil moisture spatial distributions changed differently with the mean soil moisture content according to the season using statistical metrics (skewness and kurtosis) (summer: 1 June to 31 August, winter: 1 November to 31 January). Daily variations in meteorological variables had different relationships with the changes in soil moisture for two seasons. Air and soil temperature changes clearly had negative relationships with the soil moisture change during the summer period while they had positive relationships during the winter period. Temporal stability testing showed that the representative soil moisture sites on a regional scale could be changed with seasonal periods, especially in the Asian monsoon region. In conclusion, these results provide evidence that there are clear differences in soil moisture patterns according to seasonal characteristics. This study might be useful for further researches relating to climate-meteorological effects on soil moisture patterns on a regional scale.
\end{abstract}

Key words: Soil moisture, Meteorological variables, Precipitation, Air temperature, Soil temperature, Insolation, Temporal stability, Seasonality

Citation: Cho, E., A. Zhang, and M. Choi, 2016: The seasonal difference in soil moisture patterns considering the meteorological variables throughout the Korean peninsula. Terr. Atmos. Ocean. Sci., 27, 907-920, doi: 10.3319/TAO.2016.07.12.01

\section{INTRODUCTION}

Soil moisture is an essential factor in hydrological, environmental, and climatic processes (Famiglietti and Wood 1994). The soil moisture content exerts a dominant control on the partitioning of precipitation into runoff, evaportranspiration, and infiltration and of net radiation into latent and sensible heat fluxes (Rodriguez-Iturbe 2000; Seneviratne et al. 2010; Tuttle and Salvucci 2016). At the same time, soil moisture dynamics are seasonally controlled by meteorological conditions according to climate regions (Entekhabi et al. 1996). Better understanding of the associations between soil moisture and meteorological factors, such as precipitation, air temperature, ground temperature, and the amount of insolation, enable hydrologists and meteorologists to improve estimations of the variances in evapotranspiration and

\footnotetext{
* Corresponding author

E-mail:mhchoi@skku.edu
}

heat fluxes on a regional scale. Previous studies found that the meteorological variables directly or indirectly influence on the temporal and spatial changes in soil moisture contents (Yang and Lau 1998; Hinkel et al. 2001; Lakshmi et al. 2003; Cho and Choi 2014). For example, intense precipitation often cannot be absorbed into the surface soil. However, continuous low-intensity precipitation allows water to be absorbed within the root-zone soil and stored in porous soils (Famiglietti et al. 1999). Soil moisture variability increases at relatively high levels with increasing rainfall during the rainy season (March - July), which is different from the winter season results. The temperature and amount of insolation also directly influences soil moisture conditions via ground surface water evaporation (Castelli et al. 1999; Lakshmi et al. 2003; Bosch et al. 2006). The growth of plants, which fluctuates seasonally, has a large relationship with the soil moisture conditions. The seasonal dynamics of meteorological variables can therefore lead to corresponding changes 
in the spatial and temporal patterns of soil moisture (Douville 2003; Rosenbaum et al. 2012). Cho and Choi (2014) identified the key impact of meteorological variables on soil moisture variations through statistical analysis.

As a follow-up study to Cho and Choi (2014), this study focuses on the spatio-temporal soil moisture patterns between two seasons (summer and winter) considering four meteorological variables that can represent the Asian Monsoon seasonal characteristics in northeast Asia. We compared the individual relationships between soil moisture variation and the variations in each variable as well as the soil moisture and variables themselves. We used daily soil moisture content and meteorological datasets, precipitation, air temperature, ground temperature, and the amount of insolation, from January 2012 to February 2013 in the Korean Peninsula as a regional scale case study. The results may lead to better understanding of the influence of meteorological variables on soil moisture variations in monsoon climate regions.

\section{DESCRIPTION OF THE STUDY AREA AND DATA SETS}

The Korean peninsula is located in northeast Asia $\left(33-39^{\circ} \mathrm{N}, 124-131^{\circ} \mathrm{E}\right)$. The climate type is a temperate monsoon climate with average annual rainfall of $1274 \mathrm{~mm}$ (Lee et al. 2008). This study area has an obvious seasonality during the study period. Two-thirds of the annual rainfall occurs from June to September. Alternatively, the precipitation during the winter season is often less than $10 \%$ of the total annual precipitation (Min et al. 2011). The air and ground temperature fluctuates significantly. In the summer season the weather is scorching hot and humid (due to the maritime pacific high barometric pressure), while the winter season is bitterly cold (primarily influenced by the Siberian air mass) (Gong and Ho 2002). The main soil textures are loam and sandy loam over the Korean peninsula. The dominant land use is agricultural with rice paddies as the major crop (59\%). Soil texture data were obtained from the Korean soil information system (http://soil.rda.go.kr). Most of land cover types were grass in this study.

The Rural Development Administration (RDA, http:// weather.rda.go.kr) provides soil moisture contents as well as various meteorological variables (Cho and Choi 2014). The soil moisture contents were measured at a depth of $10 \mathrm{~cm}$ to understand the near-surface and root-zone soil moisture influence on the growth of various crops and plants. In the RDA network, time domain reflectometry (TDR) soil moisture sensors were used, which are precise automatable instruments that can be used to measure the soil water content and electrical conductivity in soil pores (Topp et al. 1980). The major advantages of TDR sensors are that their measurement accuracy is higher within $1-2 \%$ volumetric water content and calibration is rarely needed (Jones et al. 2002). We used meteorological datasets, the amount of insolation (shortwave radiation), air/ground temperature and precipitation, for evaluating the meteorological factors effects on seasonal soil moisture patterns over the Korean peninsula. This data were recorded between 1 January 2012 and 28 February 2013 at 23 sites in the southern Korean peninsula (Fig. 1 and Table 1).

\section{METHODOLOGY}

We performed basic statistical analysis to display the spatial and temporal soil moisture distribution characteristics. The statistical parameters, such as the standard deviation, coefficient of variation, skewness and kurtosis, were used for the study period over 23 sites. We also compared the relationships between these parameters and the mean soil moisture contents according to the summer and winter seasons.

We calculated the daily change in each factor to grasp the variability in the meteorological data. We next performed data standardization using the following equations:

$x_{\text {standardized }}=\frac{x-\bar{x}}{\sigma}$

$\Delta x_{t}=x_{t}-x_{t-1}$

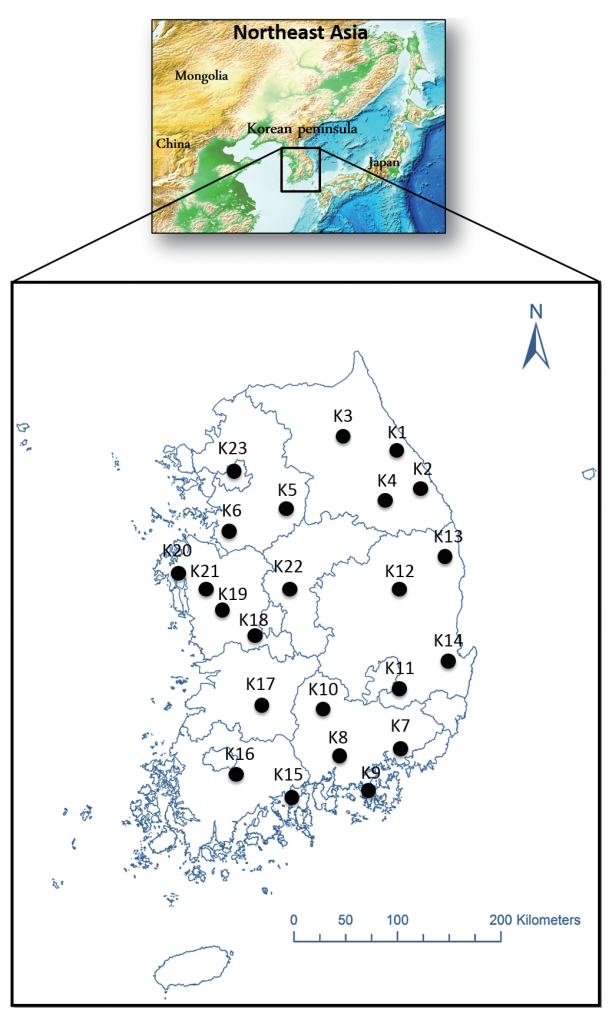

Fig. 1. Overview of the study region with the Rural Development Administration (RDA) network in the Korean peninsula. (Color online only) 


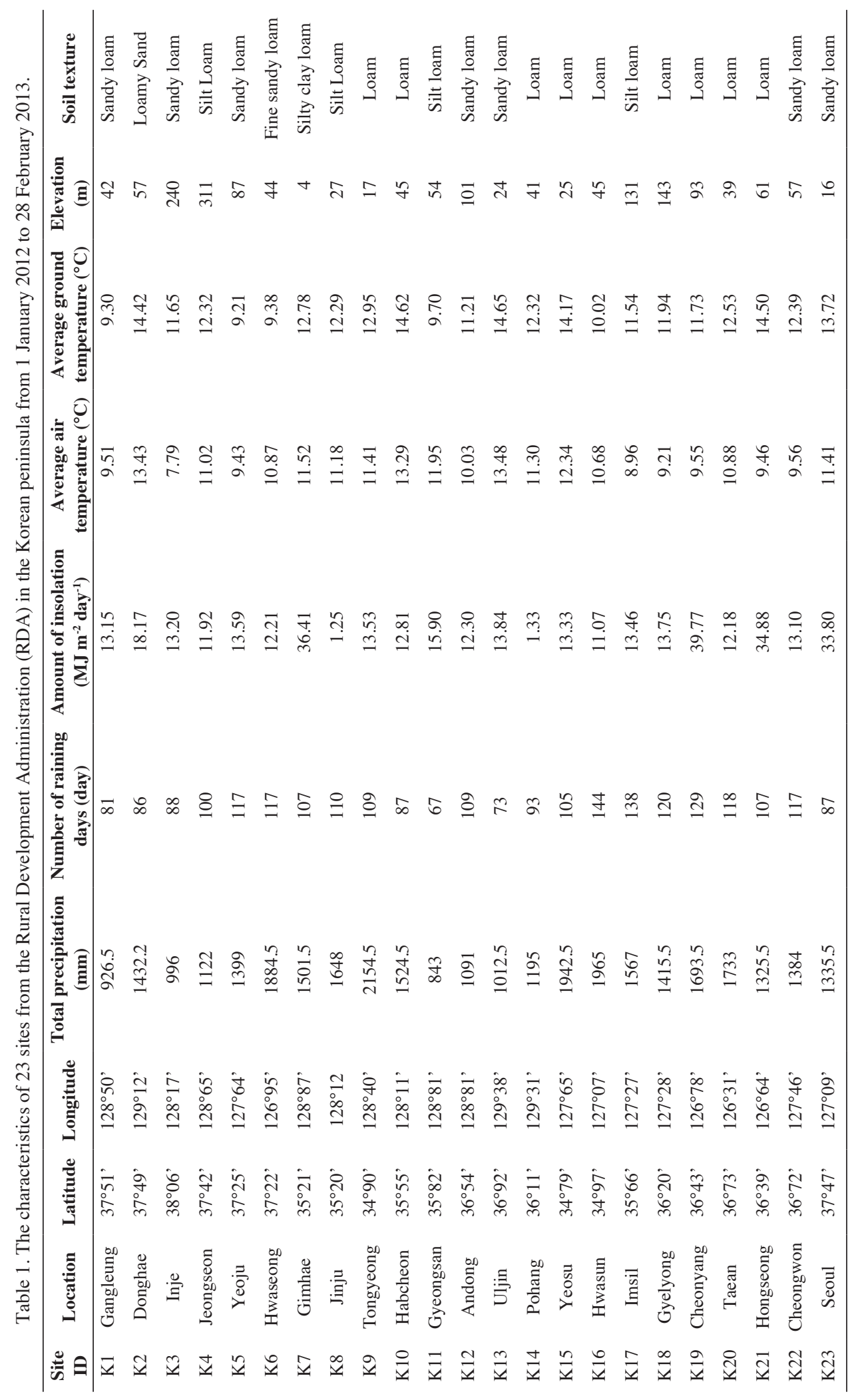


We compared these data with regards to the meteorological variables and soil moisture, using a trend line and the $\mathrm{R}$-value to analyze how much influence changes in the meteorological variables had on the soil moisture. In addition, we analyzed the winter and summer data to study the differences in the relationships between the soil moisture and meteorological variables during the winter and summer.

We calculated the mean relative difference (MRD) and the root mean squared error (RMSE) values to find the representative sites. These values were based on the relative differences and can be expressed using Eq. (3):

$\mathrm{RD}_{i, t}=\frac{\theta_{i, t}-\theta_{t}}{\bar{\theta}_{t}}$

Here, $\theta_{i, t}$ is the daily measurement of soil moisture at site $i$, and $\bar{\theta}_{t}$ is the mean soil moisture of all of the sites. For each site, the MRD value was calculated using Eq. (4), as follows:

$$
\mathrm{MRD}_{i}=\frac{1}{N_{t}} \sum_{t=1}^{N_{t}} \mathrm{RD}_{i, t}
$$

\section{RESULTS AND DISCUSSION}

\subsection{Seasonal Differences in Spatial Soil Moisture Distributions}

Figure 2a shows the standard deviation for the soil moisture versus the mean soil moisture content. The standard deviation ranged from $7.0-12.5 \%$ and the mean moisture values ranged from $19.5-40.1 \%$ in wetter conditions. The figure shows a negative relationship in that the standard deviation decreases as the mean soil moisture content increases. This result corresponds with the results from previous studies (Choi and Jacobs 2007; Famiglietti et al. 2008; Sur et al. 2013). Figure $2 \mathrm{~b}$ shows the relationship between the $\mathrm{CV}$ values and mean soil moisture content. CV had a clearly negative relationship with the mean soil moisture content. This pattern was also similar to the patterns previously achieved by Owe et al. (1982) and Brocca et al. (2007). However, the CV values $(0.18-0.54)$ in this study were higher than those reported in previous studies at similar soil moisture values. This result may be due to torrential rainfall events that occurred during the summer monsoon season. The change in the skewness values with mean soil moisture content show that the skewness decreased as the mean soil moisture increased from 20 - 40\% (Fig. 2c). Figure 2d displays a U-shaped kurtosismean soil moisture relationship. When the kurtosis value was close to zero, the soil moisture values followed a normal distribution shape. However, if the kurtosis value was high or low, the soil moisture distributions had an abnormal distribution shape. The kurtosis data decreased as the mean soil moisture increased up to $30 \%$. However, when the soil moisture values were above $30 \%$ in wet conditions, the kurtosis data showed an increasing pattern. This result corresponds with those of Famiglietti et al. (1999) and Cho and Choi (2014).

We compared the summer and winter conditions calculating statistical values separately to show how the soil moisture varies according to the season (Figs. 3a-d). These figures allow us to observe and compare daily soil moisture distributions with changing mean soil moisture contents. Figure 3a shows the relationship between the standard deviation and the mean soil moisture contents for the summer and winter seasons. These results indicated that both seasons tend to have similar trends and that the standard deviation dwindles slightly as the soil moisture content increases. When the mean soil moisture was over 30\%, a small difference in the two datasets was observed. While the summer data constantly decreased by $38 \%$, the winter data decreased by approximately $30 \%$. This indicates that heavy rainfall events occurred and influenced the soil moisture patterns more significantly during the summer season than in the winter season. Figure $3 \mathrm{~b}$ shows that the $\mathrm{CV}$ values were quite similar during both seasons, which indicates that the $\mathrm{CV}$ values were not affected by the seasonality. The change in the skewness during the summer and winter seasons is shown in Fig. 3c. The skewness continually decreased with the wetness (approaching 40\%) for the entire range of mean soil moistures. This result corresponds with the results of Famiglietti et al. (2008), who showed empirically negativefit curves of skewness versus the mean soil moisture content (on a $50 \mathrm{~km}$ scale). However, there was a clear distinction between summer and winter seasons with noticeably different shapes (Fig. 3c). The skewness during the summer season was similar to the normal patterns shown in previous studies (Ryu and Famiglietti 2005; Choi and Jacobs 2007; Famiglietti et al. 1999, 2008; Cho and Choi 2014). Alternatively, positive curves between the skewness and mean soil moisture were observed with increasing soil moisture content up until 33\% during the winter season. In addition, the skewness variability differed within a wider range with the mean soil moisture content (28\%). A possible explanation for this result is that the large locational differences caused by the extreme soil moisture values at several sites during the winter period. The kurtosis showed values that ranged from -1.6 to 0.9 , and the shape of the distribution tended to be a U-shaped curve during the summer season (Fig. 3d). The kurtosis ranged from -1.4 to 0.5 with an opposite Ushaped distribution curve during the winter season. The kurtosis value during the summer increased when the mean soil moisture content exceeded $31.5 \%$. Alternatively, the kurtosis value during the winter decreased when the mean soil moisture content exceeded $26.7 \%$. These patterns are relatively small differences, compared to the skewness and kurtosis variability in summer. This result might be due to the different seasonal characteristics but also different changes in spatial soil moisture distributions among 23 sites over the 

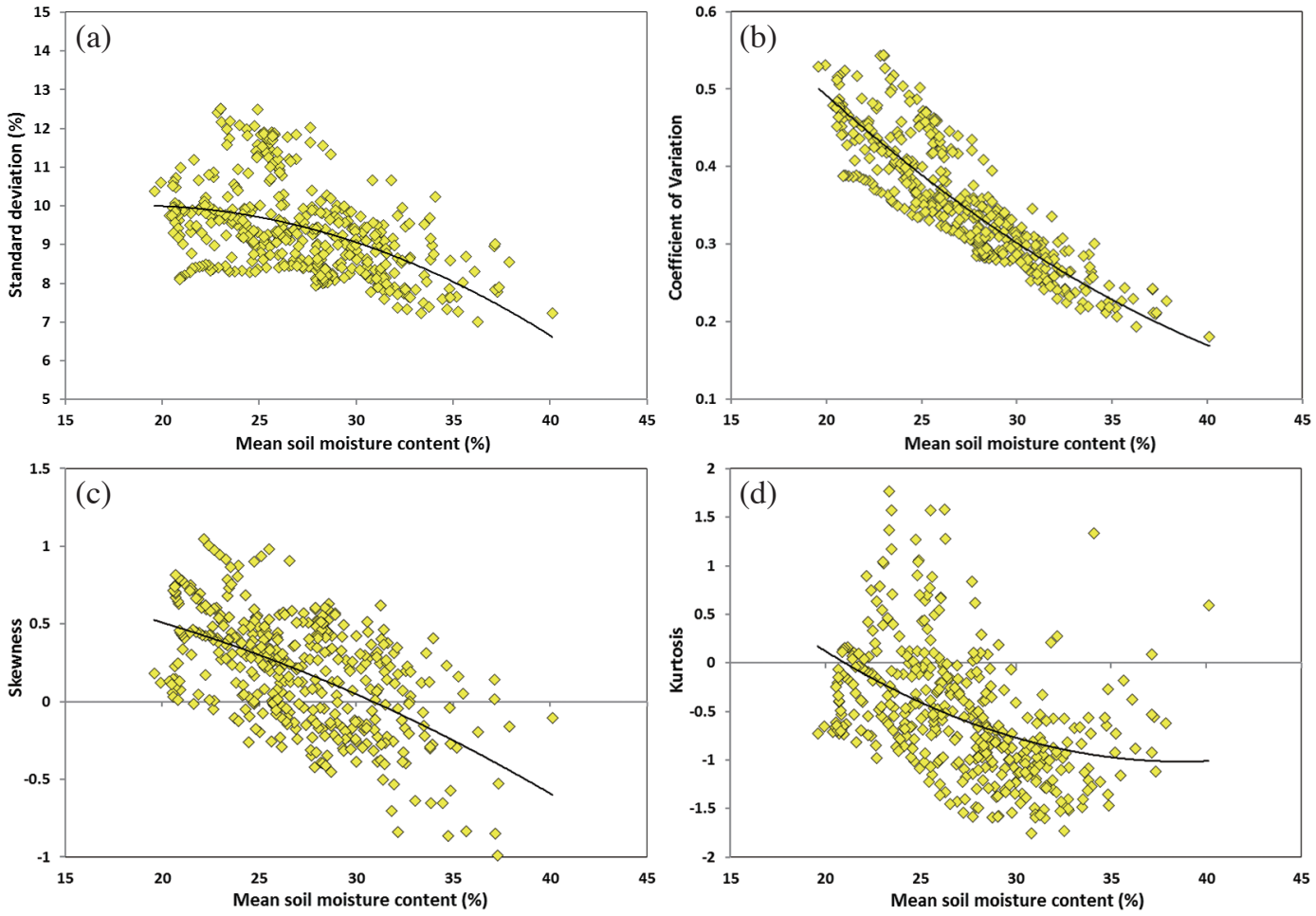

Fig. 2. Standard deviation, coefficient of variation (CV), skewness, and kurtosis versus with mean soil moisture contents [(a) - (d)] over the Korean peninsula. (Color online only)
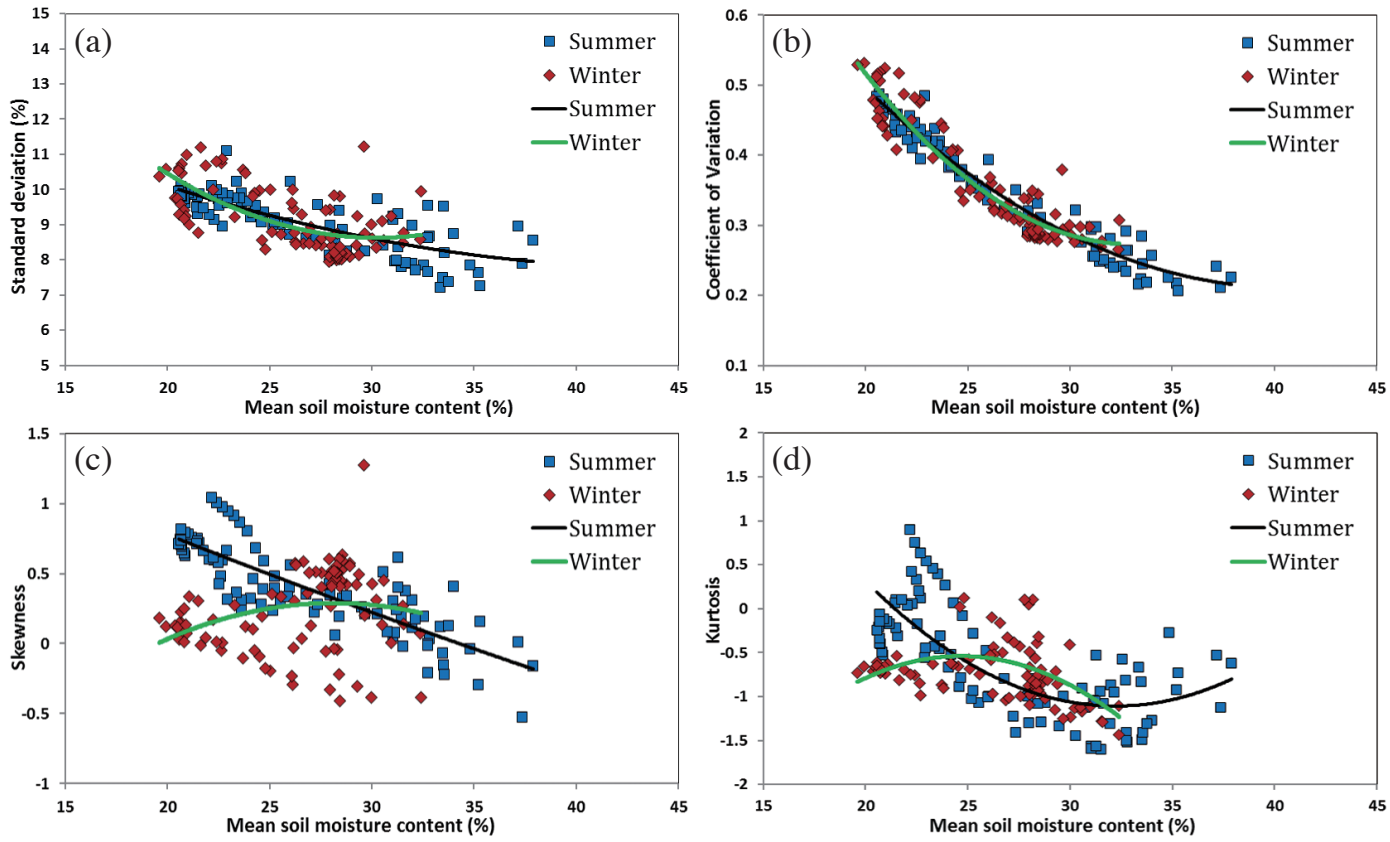

Fig. 3. Same as Fig. 2, but the data in summer (1 June to 31 August) and winter (1 November to 31 January) seasons separately over the Korean peninsula. (Color online only) 
Korean peninsula. In particular, the form of precipitation is snowfall during winter season. This means that snowpack does not directly influence temporal soil moisture variability rather as does rainfall events. The big ranges in skewness and kurtosis around the middle mean soil moisture content range (25 - 27\%) might be due to the difference in freezethaw event timing according to spatial meteorological conditions (Yang et al. 2003).

\subsection{Seasonal Impact of the Meteorological Variables on Soil Moisture}

Meteorological variables have a key influence on the land surface water-energy distribution and freezing-thawing processes during the winter season. Previous studies have shown that the primary factors that affect the soil moisture content are meteorological variables such as precipitation, temperature, insolation, and evapotranspiration (Entin et al. 2000; Seneviratne et al. 2010; Cho and Choi 2014).

Figure 4 displays the annual precipitation, soil moisture, insolation, air temperature, and ground temperature temporal patterns for the Tongyeong site. In general, the air and ground temperatures and the amount of insolation clearly showed temporal patterns that changed with the season, increasing from winter (January) to summer (August) and then decreasing from summer (August) to winter (December). The time series also displayed soil moisture patterns after rainfall events with seasonal periods. During the summer period the soil moisture declined rapidly after a pre- cipitation event. Alternatively, the soil moisture decreased slowly before the next rainfall event during the winter period. Therefore, we determined that the temporal variations in soil moisture before and after rainfall events were different for the two seasons. This result was probably due to the fact that the evaporation rates on the land surface during summer are more rapid than in the winter season.

Scatter plots between daily change in standardized soil moisture and daily change in standardized meteorological variables are shown in Fig. 5. We considered that the meteorological impact on the soil moisture is great when the line slope is steep. The scatter plots show the relationship between the soil moisture and the air/ground temperature change for the entire study period (Figs. 5a and b; Tables 2 and 3). Soil moisture change has an obvious negative relationship with temperature change during the summer. However, this shows a positive relationship during the winter. These patterns are also shown in soil moisture and air (ground) temperature time series in the summer and winter seasons (Fig. 6). The results indicate that the increase in soil moisture leads to radiative energy being absorbed in the summer season (Jin and Mullens 2014). An increase in temperature leads to freezing water and snowpack thaw on the soil surface, which causes the soil moisture content to eventually increase in the winter season (Yang et al. 2003). We also found that the soil moisture variations are more sensitive to changes in ground temperature than changes in air temperature based on the scatter plot and R-value gradients (Figs. 5a and b).

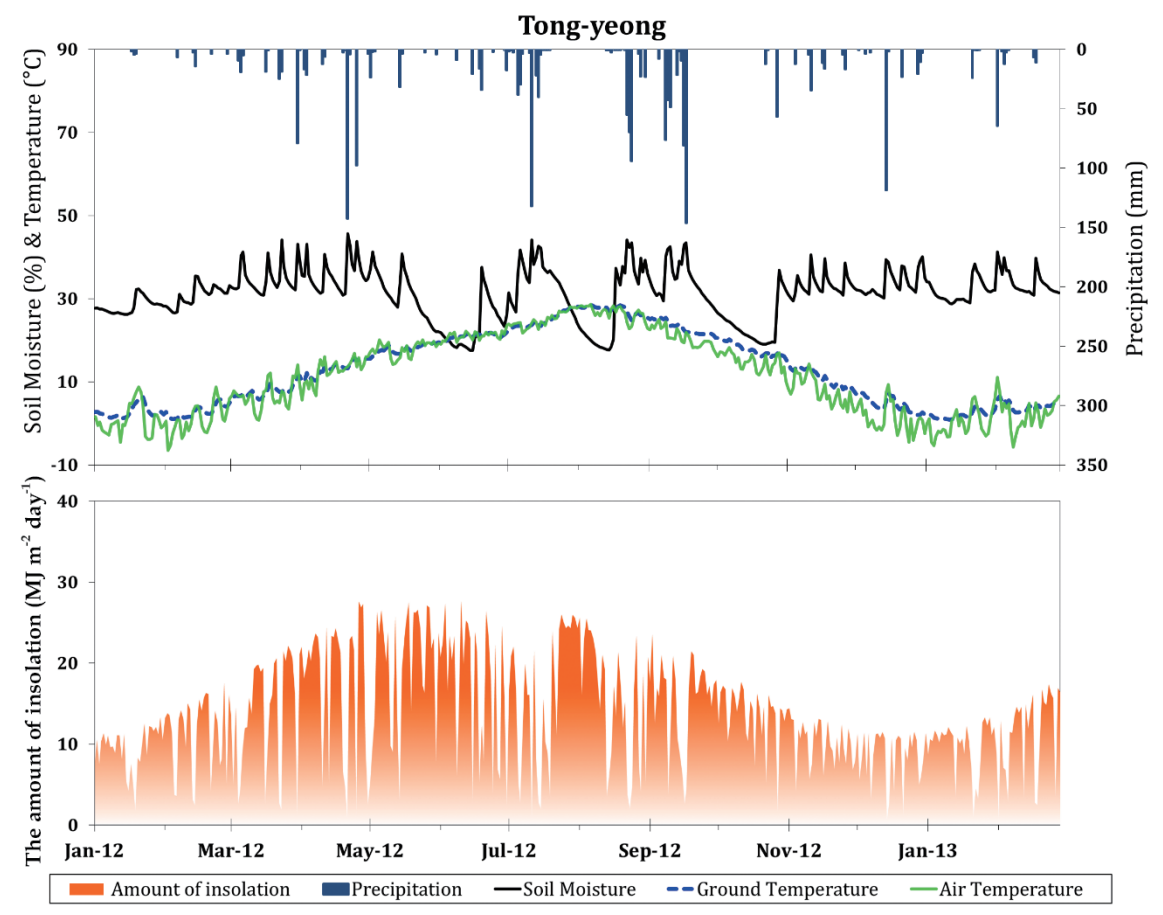

Fig. 4. Time series for precipitation, soil moisture, amount of insolation, and air and ground temperatures for the Tong-Yeong site. (Color online only) 


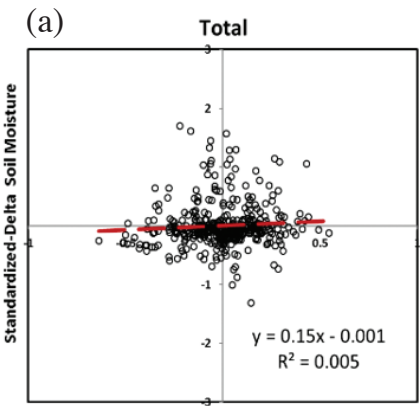

Standardized-Delta (Air) temperature

(b)

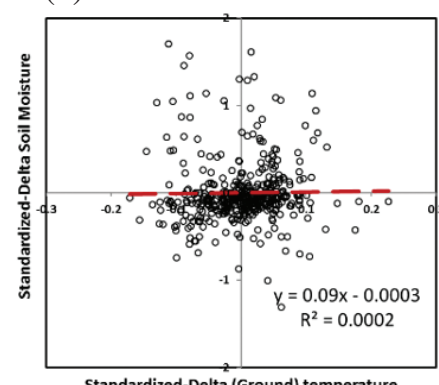

Standardized-Delta (Ground) temperature

(c)

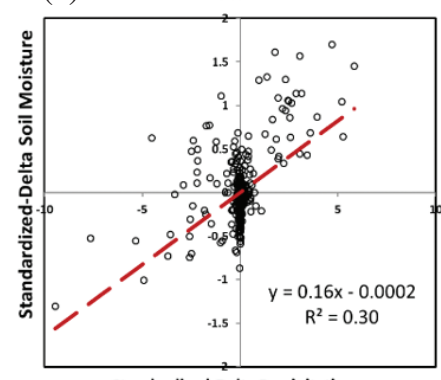

Standardized-Delta Precipitation

(d)

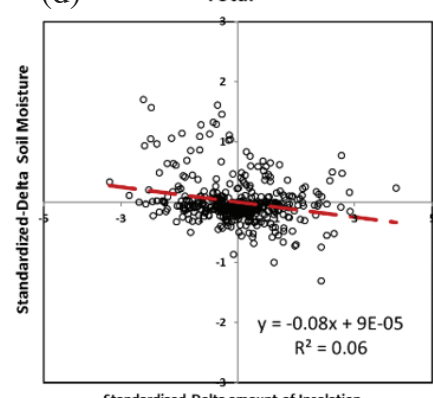

Standardized-Delta amount of Insolation

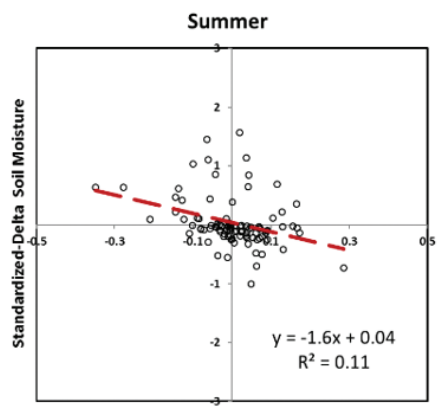

Standardized-Delta (Air) temperature

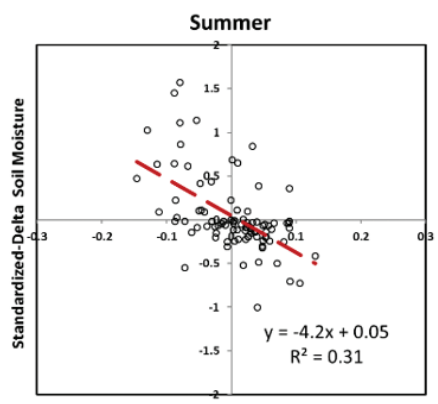

Standardized-Delta (Ground) temperature

Summer

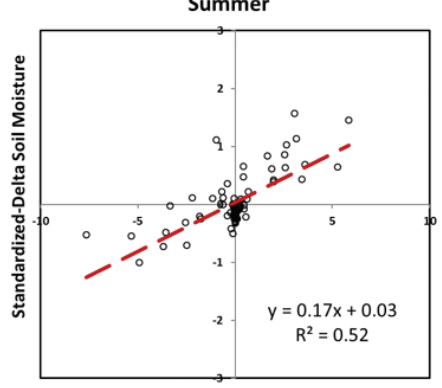

Standardized-Delta Precipitation

Summer

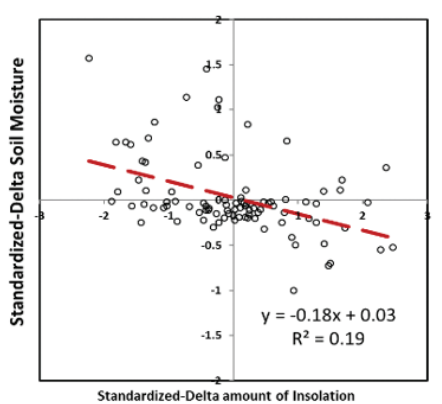

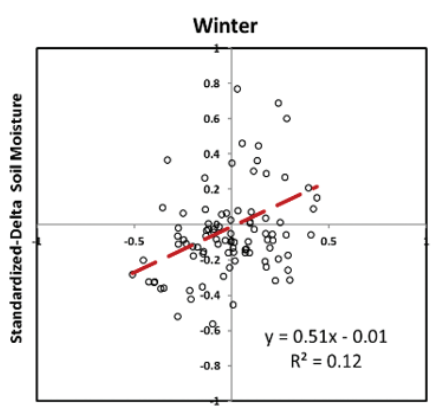

Standardized-Delta (Air) temperature

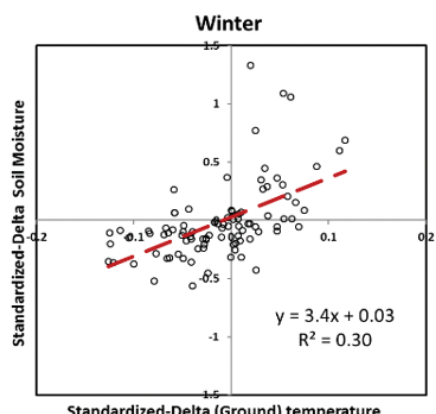

Standardized-Delta (Ground) temperature

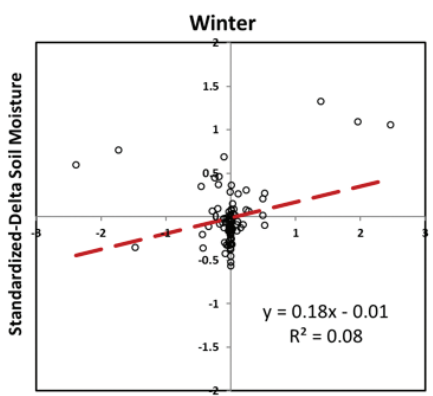

Standardized-Delta Precipitation

Winter

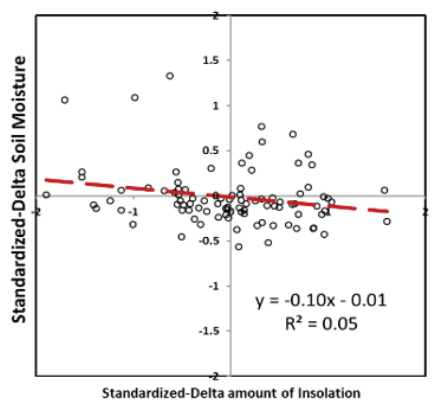

Fig. 5. Scatter plots of mean soil moisture change and (a) air temperature change, (b) ground temperature change, (c) precipitation change, and (d) amount of insolation change. (Color online only) 
Table 2. Statistics between standardized soil moisture change and air temperature change from 1 January 2012 to 28 February 2013.

\begin{tabular}{|c|c|c|c|c|c|c|c|}
\hline \multirow{2}{*}{ Site ID } & \multirow{2}{*}{ Location } & \multicolumn{2}{|r|}{ Summer } & \multicolumn{2}{|r|}{ Winter } & \multicolumn{2}{|r|}{ Total } \\
\hline & & $\mathbf{R}$ & Equation & $\mathbf{R}$ & Equation & $\mathbf{R}$ & Equation \\
\hline K1 & Gangleung & $0.36 * *$ & $y=-0.43 x+0.026$ & $0.13 * *$ & $y=0.09 x-0.021$ & 0.06 & $y=-0.09 x-0.003$ \\
\hline K2 & Donghae & $0.29 * *$ & $y=-0.21 x+0.023$ & $0.26^{* *}$ & $y=0.20 x+0.035$ & 0.06 & $y=-0.10 x+0.001$ \\
\hline K3 & Inje & $0.29 * *$ & $y=-0.15 x+0.030$ & $0.11 *$ & $y=0.03 x-0.023$ & 0.08 & $y=-0.07 x+0.000$ \\
\hline K4 & Jeonseong & $0.42 * *$ & $y=-0.44 x+0.034$ & $0.10^{*}$ & $y=0.03 x-0.020$ & 0.04 & $y=-0.06 x+0.010$ \\
\hline K5 & Yeoju & $0.47 * *$ & $y=-0.54 x+0.039$ & $0.18^{*}$ & $y=0.12 x-0.016$ & $0.10 *$ & $y=-0.28 x+0.002$ \\
\hline K6 & Hwaseong & $0.42 * *$ & $y=-0.27 x+0.026$ & $0.13^{*}$ & $y=-0.06 x-0.022$ & $0.28 * *$ & $y=-0.38 x+0.003$ \\
\hline K7 & Gimhae & $0.54 * *$ & $y=0.28 x+0.010$ & $0.28 * *$ & $y=0.54 x+0.003$ & $0.35^{* *}$ & $\mathrm{y}=0.87 \mathrm{x}-0.001$ \\
\hline K8 & Jinju & $0.27 * *$ & $y=0.09 x+0.019$ & $0.52 * *$ & $y=0.58 x+0.010$ & $0.37 * *$ & $y=0.74 x-0.003$ \\
\hline K9 & Tongyeong & $0.10 *$ & $y=-0.11 x+0.021$ & $0.44 * *$ & $y=0.68 x+0.007$ & $0.25^{* *}$ & $y=0.56 x+0.001$ \\
\hline K10 & Habcheon & $0.27 * *$ & $y=-0.27 x+0.030$ & $0.12 *$ & $y=0.33 x-0.009$ & 0.03 & $y=0.08 x+0.00$ \\
\hline K11 & Gyeongsan & $0.26^{* *}$ & $y=0.12 x+0.026$ & $0.21^{*}$ & $y=0.18 x-0.001$ & $0.17^{*}$ & $y=0.37 x+0.002$ \\
\hline K12 & Andong & $0.29 * *$ & $\mathrm{y}=0.27 \mathrm{x}-0.018$ & $0.26^{* *}$ & $y=0.20 x-0.011$ & $0.13^{*}$ & $y=0.19 x-0.004$ \\
\hline K13 & Uljin & $0.28 * *$ & $y=-0.34 x+0.028$ & $0.28 * *$ & $y=0.36 x+0.001$ & 0.07 & $y=0.18 x+0.001$ \\
\hline K14 & Pohang & $0.70 * *$ & $y=0.46 x+0.030$ & $0.36^{* *}$ & $y=0.44 x+0.008$ & $0.41 * *$ & $y=0.67 x+0.001$ \\
\hline K15 & Yeosu & 0.03 & $y=-0.02 x+0.022$ & $0.24 * *$ & $y=0.28 x+0.024$ & $0.16^{*}$ & $y=0.25 x+0.002$ \\
\hline K16 & Hwasun & $0.89 * *$ & $y=0.92 x+0.010$ & 0.07 & $y=0.03 x-0.011$ & $0.17^{*}$ & $y=1.88 x+0.002$ \\
\hline K17 & Imsil & $0.22 * *$ & $y=-0.22 x+0.019$ & 0.01 & $y=-0.01 x-0.015$ & $0.10^{*}$ & $y=-0.23 x+0.003$ \\
\hline K18 & Gyelyong & $0.37 * *$ & $y=-0.38 x+0.024$ & $0.42 * *$ & $y=0.57 x+0.037$ & $0.13^{*}$ & $y=0.39 x+0.001$ \\
\hline K19 & Cheonyang & $0.39 * *$ & $y=-0.45 x+0.033$ & $0.24 * *$ & $y=0.20 x+0.001$ & $0.05^{*}$ & $y=0.12 x+0.002$ \\
\hline K20 & Taean & $0.50 * *$ & $y=0.26 x+0.015$ & 0.03 & $y=-0.04 x-0.015$ & $0.20 *$ & $y=0.49 x-0.001$ \\
\hline K21 & Hongseong & $0.90 * *$ & $y=0.88 x+0.012$ & $0.10 *$ & $y=0.03 x-0.019$ & $0.55^{* * *}$ & $y=0.97 x-0.001$ \\
\hline K22 & Cheongwon & $0.45^{* *}$ & $y=-0.40 x+0.031$ & $0.10^{*}$ & $y=0.05 x-0.023$ & $0.08^{*}$ & $y=-0.16 x+0.003$ \\
\hline $\mathrm{K} 23$ & Seoul & $0.48 * *$ & $y=-0.48 x+0.034$ & $0.21 *$ & $\mathrm{y}=0.078 \mathrm{x}-0.021$ & $0.20 * *$ & $y=-0.51 x-0.001$ \\
\hline \multicolumn{2}{|c|}{ Average } & 0.40 & A: $-0.06, B: 0.023$ & 0.21 & A: 0.21, B: 0.004 & 0.18 & A: $0.26, \mathrm{~B}: 0.001$ \\
\hline
\end{tabular}

Note: $y=A x+B, x=$ daily difference in standardized soil moisture and $y=$ daily difference in standardized air temperature.

Table 3. Statistics between standardized soil moisture change and ground temperature change.

\begin{tabular}{|c|c|c|c|c|c|c|c|}
\hline \multirow{2}{*}{ Site ID } & \multirow{2}{*}{ Location } & \multicolumn{2}{|r|}{ Summer } & \multicolumn{2}{|r|}{ Winter } & \multicolumn{2}{|r|}{ Total } \\
\hline & & $\mathbf{R}$ & Equation & $\mathbf{R}$ & Equation & $\mathbf{R}$ & Equation \\
\hline K1 & Gangleung & $0.29 * *$ & $y=-0.64 x+0.034$ & $0.26 * *$ & $y=0.43 x-0.010$ & 0.07 & $y=-0.45 x-0.003$ \\
\hline $\mathrm{K} 2$ & Donghae & $0.42 * *$ & $y=-0.52 x+0.026$ & 0.08 & $y=-0.14 x+0.013$ & $0.17^{*}$ & $y=-0.86 x-0.002$ \\
\hline $\mathrm{K} 3$ & Inje & $0.41 * *$ & $y=-0.21 x+0.030$ & $0.29 * *$ & $y=0.09 x-0.011$ & $0.11^{*}$ & $y=-0.15 x+0.000$ \\
\hline K4 & Jeonseong & $0.53 * *$ & $y=-0.69 x+0.032$ & $0.61 * *$ & $y=0.42 x-0.005$ & $0.22 * *$ & $y=-0.73 x+0.007$ \\
\hline K5 & Yeoju & $0.15^{*}$ & $y=-0.66 x+0.050$ & $0.24 * *$ & $y=0.32 x-0.008$ & 0.03 & $y=-0.36 x+0.002$ \\
\hline K6 & Hwaseong & $0.11^{*}$ & $y=-0.33 x+0.033$ & $0.36^{* *}$ & $y=0.40 x-0.009$ & 0.07 & $y=0.69 x+0.003$ \\
\hline K7 & Gimhae & $0.57 * *$ & $y=0.28 x+0.010$ & $0.24 * *$ & $y=0.88 x-0.003$ & $0.41 * *$ & $y=1.45 x-0.001$ \\
\hline K8 & Jinju & $0.25 * *$ & $y=0.08 x+0.019$ & $0.29 * *$ & $y=0.57 x+0.011$ & $0.23 * *$ & $y=0.63 x-0.003$ \\
\hline K9 & Tongyeong & $0.21 *$ & $y=-0.66 x+0.034$ & $0.26 * *$ & $y=0.89 x+0.002$ & $0.26 * *$ & $y=1.95 x-0.000$ \\
\hline K10 & Habcheon & $0.44 * *$ & $y=-0.73 x+0.035$ & $0.35^{* *}$ & $y=0.56 x-0.000$ & $0.23 * *$ & $y=-1.61 x-0.005$ \\
\hline K11 & Gyeongsan & $0.28 * *$ & $y=0.17 x+0.022$ & $0.27 * *$ & $y=0.43 x+0.002$ & $0.19 *$ & $y=0.64 x+0.003$ \\
\hline K12 & Andong & $0.28 * *$ & $y=0.16 x-0.016$ & $0.33 * *$ & $y=0.50 x+0.002$ & 0.06 & $y=0.11 x-0.004$ \\
\hline $\mathrm{K} 13$ & Uljin & $0.44 * *$ & $y=-0.76 x+0.03$ & $0.14^{*}$ & $y=0.37 x+0.004$ & $0.14^{*}$ & $y=-1.00 x-0.003$ \\
\hline K14 & Pohang & $0.83 * *$ & $y=0.50 x+0.024$ & $0.29 * *$ & $y=0.72 x+0.012$ & $0.57 * *$ & $y=1.43 x+0.001$ \\
\hline K15 & Yeosu & $0.24 * *$ & $y=-0.23 x+0.025$ & $0.03 * *$ & $y=0.08 x+0.004$ & $0.11^{*}$ & $y=0.44 x+0.002$ \\
\hline K16 & Hwasun & $0.97 * *$ & $y=0.99 x+0.007$ & $0.28 * *$ & $y=0.33 x-0.002$ & $0.93 * *$ & $y=5.08 x+0.004$ \\
\hline K17 & Imsil & $0.36 * *$ & $y=-1.14 x+0.038$ & $0.05^{*}$ & $y=-0.07 x-0.019$ & $0.12^{*}$ & $y=-1.08 x+0.003$ \\
\hline K18 & Gyelyong & $0.50 * *$ & $y=-1.09 x+0.034$ & $0.77 * *$ & $y=2.01 x+0.006$ & $0.46 * *$ & $y=3.08 x-0.000$ \\
\hline K19 & Cheonyang & $0.59 * *$ & $y=-0.90 x+0.034$ & $0.24 * *$ & $y=0.38 x+0.007$ & $0.13^{*}$ & $y=-0.78 x+0.003$ \\
\hline K20 & Taean & $0.58 * *$ & $y=0.23 x+0.016$ & 0.03 & $y=0.07 x-0.012$ & $0.47 * *$ & $y=1.54 x-0.001$ \\
\hline K21 & Hongseong & $0.92 * *$ & $y=0.76 x+0.015$ & $0.19^{*}$ & $y=0.06 x-0.012$ & $0.61 * *$ & $y=0.99 x-0.001$ \\
\hline K22 & Cheongwon & $0.53 * *$ & $y=-0.79 x+0.036$ & $0.37 * *$ & $y=0.36 x-0.013$ & $0.13^{*}$ & $y=-0.84 x+0.003$ \\
\hline $\mathrm{K} 23$ & Seoul & $0.56 * *$ & $y=-0.86 x+0.044$ & $0.57 * *$ & $y=0.43 x-0.010$ & $0.40 * *$ & $y=-2.87 x-0.013$ \\
\hline \multicolumn{2}{|c|}{ Average } & 0.45 & A: $-0.31, B: 0.027$ & 0.28 & A: 0.44, B: 0.002 & 0.27 & A: $0.32, B:-0.001$ \\
\hline
\end{tabular}

Note: $y=A x+B, x=$ daily difference in standardized soil moisture and $y=$ daily difference in standardized ground temperature. *, ** indicate significance at the 0.05 and 0.01 probability level. 

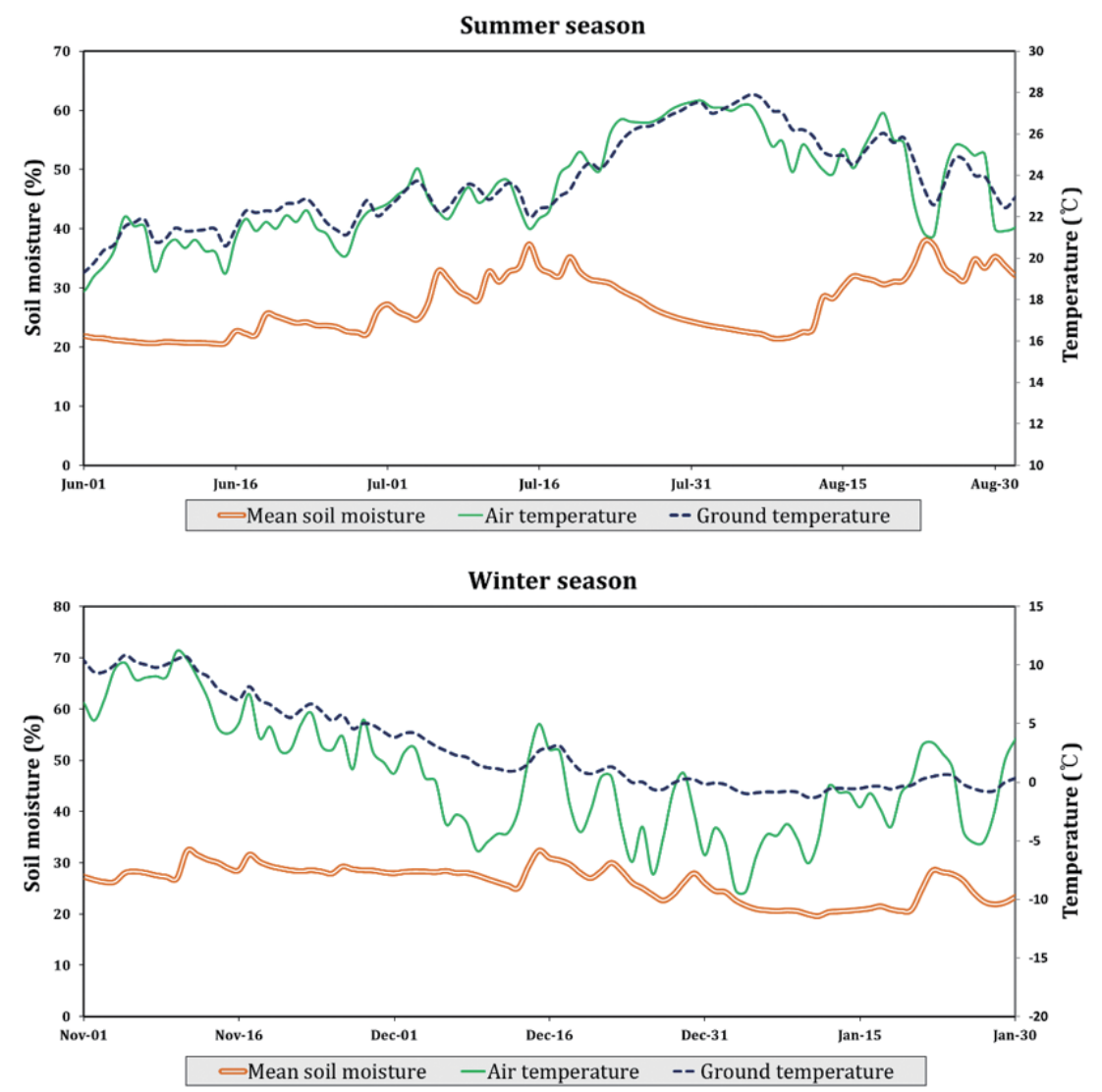

Fig. 6. Temporal patterns of mean soil moisture and mean air (ground) temperature over 23 sites in summer and winter seasons. (Color online only)

Figure $5 \mathrm{c}$ and Table 4 show the relationship between the precipitation change and the soil moisture change. The curve line gradient between the precipitation and soil moisture was the highest among all of the variables. This result indicates that the precipitation was a dominant factor that led to changes in the soil moisture. Precipitation had a clear positive relationship with soil moisture during both winter and summer seasons. However, the $\mathrm{R}^{2}$ for the two seasons were significantly different: 0.52 during the summer and 0.08 during the winter. This means that precipitation during the summer period has a clear effect on the changes in soil moisture content as opposed to the winter period. This is probably due to the complicated snow crystal accumulation and snowpack melting procedure in winter as well as the difference in rainfall intensity between the two seasons. The relationship between the amount of insolation and the soil moisture is presented in Fig. 5d and Table 5. Insolation is a measure of the solar radiation energy. Even though the insolation showed large fluctuations throughout the entire period, it clearly showed a negative relationship with the soil moisture. This result may due to the fact that the amount of insolation directly influences the amount of evapotranspiration. In summer, the change in insolation with a change in soil moisture had a negative trend with an R-value of 0.44 . Alternatively, the amount of insola- tion influence on the soil moisture change was weaker during the winter $(\mathrm{R}=0.22)$. This result implies that the temporal and spatial variations in insolation and soil moisture content are linked to each other in terms of the water and energy cycle in the land surface-atmosphere system (Seneviratne et al. 2010; Van den Hurk et al. 2012).

\subsection{Seasonal Difference in Temporal Stability of Soil Moisture}

The time-stable points represent the regional mean soil moisture in a region. We estimated the MRD and the RMSE values to obtain temporal stable sites for the surface soil moisture contents. In other words, the best sites had MRD and RMSE values that were close to zero. The 23 sample sites were ranked in terms of their MRD to conduct temporal stability analyses, as shown in Fig. 7. We obtained ranked plots of the MRD and RMSE values for the 23 sites for the entire study period. The MRD and RMSE values ranged from $-52 \%$ (K3) to $119 \%$ (K20) and $12.5 \%$ (K17) to $119 \%$ (K20), respectively (Fig. 7a). We determined that the MRD and RMSE values for the 23 sites varied according to the investigation period. Figures $7 \mathrm{~b}$ and $\mathrm{c}$ show the rank plots for the mean soil moisture, MRD and RMSE values during 
Table 4. Statistics between standardized soil moisture change and precipitation change.

\begin{tabular}{|c|c|c|c|c|c|c|c|}
\hline \multirow{2}{*}{ Site ID } & \multirow{2}{*}{ Location } & \multicolumn{2}{|r|}{ Summer } & \multicolumn{2}{|r|}{ Winter } & \multicolumn{2}{|r|}{ Total } \\
\hline & & $\mathbf{R}$ & Equation & $\mathbf{R}$ & Equation & $\mathbf{R}$ & Equation \\
\hline K1 & Gangleung & $0.62 * *$ & $y=0.25 x-0.005$ & $0.24 * *$ & $y=-0.07 x-0.017$ & $0.39 * *$ & $y=0.10 x-0.003$ \\
\hline K2 & Donghae & $0.84 * *$ & $y=0.21 x+0.017$ & - & - & $0.69 * *$ & $y=0.19 x+0.001$ \\
\hline $\mathrm{K} 3$ & Inje & $0.70 * *$ & $y=0.15 x-0.022$ & $0.15^{*}$ & $y=0.02 x-0.012$ & $0.25^{* *}$ & $y=0.02 x+0.002$ \\
\hline K4 & Jeonseong & $0.70 * *$ & $y=0.24 x+0.032$ & $0.19^{*}$ & $y=0.03 x+0.001$ & $0.41 * *$ & $y=0.10 x+0.010$ \\
\hline K5 & Yeoju & $0.56^{* *}$ & $y=0.24 x-0.002$ & $0.20 * *$ & $y=0.04 x+0.001$ & $0.30 * *$ & $y=0.12 x+0.002$ \\
\hline K6 & Hwaseong & $0.65 * *$ & $y=0.08 x-0.034$ & $0.23 * *$ & $y=-0.04 x+0.031$ & $0.30 * *$ & $y=0.064 x+0.003$ \\
\hline K7 & Gimhae & $0.23 * *$ & $y=0.10 x+0.046$ & 0.02 & $y=-0.02 x+0.280$ & $0.21^{*}$ & $y=0.10 x+0.000$ \\
\hline K8 & Jinju & $0.51 * *$ & $y=0.18 x+0.005$ & $0.35^{* *}$ & $y=0.11 x+0.150$ & $0.46^{* *}$ & $y=0.18 x-0.002$ \\
\hline K9 & Tongyeong & $0.63 * *$ & $\mathrm{y}=0.19 x-0.019$ & $0.35^{* *}$ & $y=0.24 x+0.250$ & 0.01 & $y=-0.01 x+0.002$ \\
\hline K10 & Habcheon & $0.84 * *$ & $y=0.37 x+0.010$ & $0.32 * *$ & $y=0.06 x+0.030$ & $0.62 * *$ & $y=0.27 x+0.000$ \\
\hline K11 & Gyeongsan & $0.51 * *$ & $y=0.21 x+0.097$ & $0.23 * *$ & $y=0.07 x+0.130$ & $0.58 * *$ & $y=0.26 x+0.002$ \\
\hline K12 & Andong & $0.73^{* *}$ & $y=-0.20 x+0.061$ & $0.46^{* *}$ & $y=-0.12 x+0.012$ & $0.17 *$ & $y=-0.04 x-0.004$ \\
\hline K13 & Uljin & $0.88 * *$ & $y=0.39 x+0.011$ & 0.02 & $y=0.01 x+0.180$ & $0.60 * *$ & $y=0.28 x+0.001$ \\
\hline K14 & Pohang & $0.14 *$ & $y=0.08 x+0.056$ & $0.05^{*}$ & $y=0.02 x+0.130$ & $0.16^{*}$ & $y=0.06 x+0.002$ \\
\hline K15 & Yeosu & $0.51 * *$ & $y=0.12 x-0.009$ & $0.23 * *$ & $y=0.11 x+0.140$ & $0.39 * *$ & $y=0.10 x+0.003$ \\
\hline K16 & Hwasun & $0.06^{* *}$ & $y=0.09 x+0.030$ & $0.12^{*}$ & $y=-0.02 x+0.050$ & $0.08 *$ & $y=0.05 x+0.004$ \\
\hline K17 & Imsil & $0.92 * *$ & $y=0.37 x-0.028$ & $0.11 *$ & $y=-0.02 x+0.007$ & $0.56^{* *}$ & $y=0.18 x+0.002$ \\
\hline K18 & Gyelyong & $0.82 * *$ & $y=0.34 x-0.019$ & 0.10 & $y=0.05 x+0.140$ & $0.52 * *$ & $y=0.26 x+0.002$ \\
\hline K19 & Cheonyang & $0.85^{* *}$ & $y=0.46 x+0.004$ & $0.56 * *$ & $y=0.15 x+0.073$ & $0.59 * *$ & $y=0.21 x+0.003$ \\
\hline K20 & Taean & $0.37 * *$ & $y=0.39 x-0.034$ & $0.64 * *$ & $y=0.23 x+0.024$ & $0.52 * *$ & $y=0.22 x-0.000$ \\
\hline K21 & Hongseong & $0.58 * *$ & $y=0.23 x-0.002$ & 0.14 & $y=0.01 x+0.022$ & $0.28 * *$ & $y=0.09 x+0.000$ \\
\hline K22 & Cheongwon & $0.62 * *$ & $y=0.32 x+0.011$ & $0.22 * *$ & $y=0.03 x+0.021$ & $0.36^{* *}$ & $y=0.10 x+0.002$ \\
\hline $\mathrm{K} 23$ & Seoul & $0.86^{* *}$ & $y=0.34 x-0.041$ & $0.21^{*}$ & $y=0.03 x+0.012$ & $0.73 * *$ & $y=0.26 x+0.000$ \\
\hline \multicolumn{2}{|c|}{ Average } & 0.61 & A: 0.22, B: 0.007 & 0.23 & A: 0.04, B: 0.079 & 0.40 & A: 0.14, B: 0.002 \\
\hline
\end{tabular}

Note: $y=A x+B, x=$ daily difference in standardized soil moisture and $y=$ daily difference in standardized precipitation.

*, ** indicate significance at the 0.05 and 0.01 probability level.

Table 5. Statistics between standardized soil moisture change and standardized insolation change.

\begin{tabular}{|c|c|c|c|c|c|c|c|}
\hline \multirow{2}{*}{ Site ID } & \multirow{2}{*}{ Location } & \multicolumn{2}{|r|}{ Summer } & \multicolumn{2}{|r|}{ Winter } & \multicolumn{2}{|r|}{ Total } \\
\hline & & $\mathbf{R}$ & Equation & $\mathbf{R}$ & Equation & $\mathbf{R}$ & Equation \\
\hline K1 & Gangleung & $0.32 * *$ & $y=-0.18 x+0.02$ & $0.15^{*}$ & $y=-0.05 x-0.014$ & 0.21 ** & $y=-0.067 x-0.0025$ \\
\hline $\mathrm{K} 2$ & Donghae & $0.15^{*}$ & $y=-0.0514 x+0.02$ & $0.19 *$ & $y=-0.071 x+0.014$ & $0.11^{*}$ & $y=-0.04 x+0.0013$ \\
\hline K3 & Inje & - & - & $0.10 *$ & $\mathrm{y}=0.014 \mathrm{x}-0.011$ & 0.09 & $y=-0.02 x+0.0003$ \\
\hline K4 & Jeonseong & $0.28 * *$ & $y=-0.15 x+0.027$ & $0.12 *$ & $y=0.02 x-0.007$ & 0.09 & $y=-0.032 x+0.01$ \\
\hline K5 & Yeoju & $0.20 *$ & $y=-0.14 x+0.033$ & 0.01 & $y=-0.004 x-0.011$ & 0.02 & $y=-0.013 x+0.002$ \\
\hline K6 & Hwaseong & $0.24 * *$ & $y=-0.076 x+0.023$ & 0.06 & $\mathrm{y}=0.014 \mathrm{x}-0.014$ & $0.11^{*}$ & $y=-0.032 x+0.003$ \\
\hline K7 & Gimhae & 0.01 & $y=0.006 x+0.014$ & 0.02 & $y=-0.013 x-0.006$ & - & - \\
\hline K8 & Jinju & $0.23 * *$ & $y=-0.083 x+0.021$ & $0.11^{*}$ & $y=-0.046 x+0.006$ & $0.13 *$ & $y=-0.057 x-0.0015$ \\
\hline K9 & Tongyeong & $0.22 * *$ & $y=-0.082 x+0.02$ & $0.28 * *$ & $y=-0.2 x-0.004$ & $0.20 * *$ & $y=-0.097 x+0.002$ \\
\hline K10 & Habcheon & $0.27 * *$ & $y=-0.13 x+0.027$ & $0.16^{*}$ & $y=-0.055 x-0.005$ & $0.21^{* *}$ & $y=-0.10 x+0.0004$ \\
\hline K11 & Gyeongsan & $0.09^{*}$ & $y=-0.048 x+0.027$ & - & - & 0.01 & $y=-0.004 x+0.001$ \\
\hline K12 & Andong & $0.15^{*}$ & $y=0.078 x-0.015$ & - & - & - & - \\
\hline K13 & Uljin & $0.14^{*}$ & $y=-0.08 x+0.022$ & $0.08 *$ & $y=-0.047 x+0.001$ & $0.13^{*}$ & $y=-0.08 x+0.0005$ \\
\hline K14 & Pohang & $0.28 * *$ & $y=0.17 x+0.037$ & $0.10 *$ & $y=-0.048 x+0.007$ & 0.04 & $y=0.018 x+0.002$ \\
\hline K15 & Yeosu & 0.05 & $y=-0.013 x+0.022$ & $0.22 * *$ & $y=-0.095 x+0.003$ & 0.08 & $y=-0.022 x+0.003$ \\
\hline K16 & Hwasun & $0.18 *$ & $y=0.22 x+0.018$ & 0.06 & $y=-0.014 x-0.0056$ & 0.09 & $y=0.074 x+0.004$ \\
\hline K17 & Imsil & $0.27 * *$ & $y=-0.12 x+0.017$ & 0.09 & $y=-0.025 x-0.018$ & 0.08 & $y=-0.032 x+0.003$ \\
\hline K18 & Gyelyong & $0.44 * *$ & $y=-0.22 x+0.02$ & $0.17 *$ & $y=0.13 x-0.015$ & $0.16^{*}$ & $y=-0.10 x+0.0022$ \\
\hline K19 & Cheonyang & $0.29 * *$ & $y=-0.15 x+0.028$ & - & - & $0.11 *$ & $y=-0.04 x+0.0022$ \\
\hline K20 & Taean & 0.09 & $y=-0.057 x+0.019$ & $0.27 * *$ & $y=-0.12 x-0.012$ & $0.12 *$ & $y=-0.08 x+0.0002$ \\
\hline K21 & Hongseong & $0.79 * *$ & $y=2.30 x+0.07$ & $0.13^{*}$ & $y=-0.021 x-0.011$ & $0.47 * *$ & $y=0.51 x+0.0018$ \\
\hline K22 & Cheongwon & $0.35^{* * *}$ & $y=-0.15 x+0.026$ & $0.10^{*}$ & $y=-0.023 x-0.016$ & $0.29 * *$ & $y=-0.11 x+0.003$ \\
\hline $\mathrm{K} 23$ & Seoul & - & - & - & - & - & - \\
\hline \multicolumn{2}{|c|}{ Average } & 0.24 & A: $0.500, B: 0.024$ & 0.13 & A: $-0.034, B:-0.006$ & 0.14 & A: $-0.016, B: 0.002$ \\
\hline
\end{tabular}

Note: $y=A x+B, x=$ daily difference in standardized soil moisture and $y=$ daily difference in standardized insolation. *, ** indicate significance at the 0.05 and 0.01 probability level. 

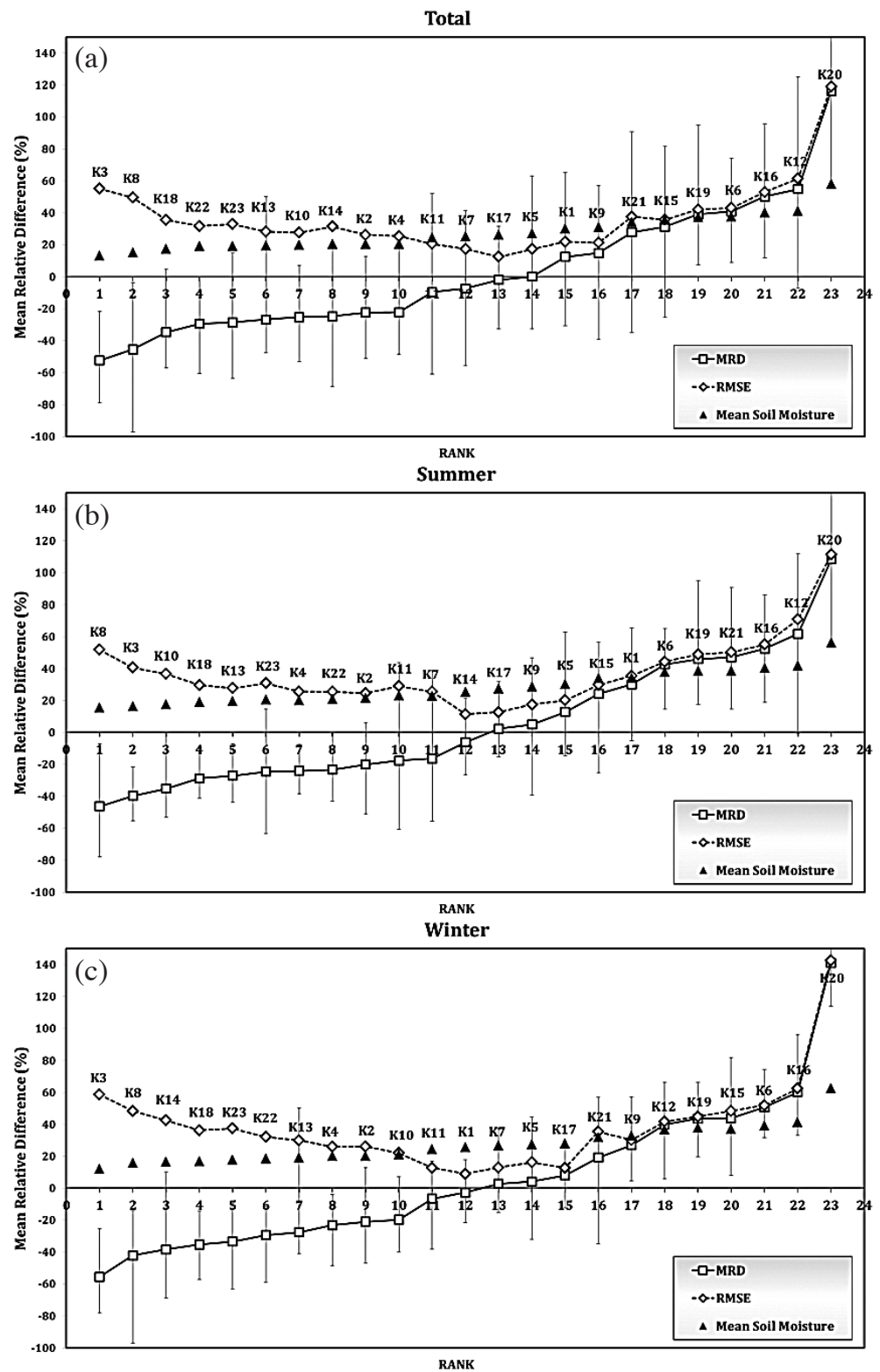

Fig. 7. Plots of the ranked mean soil moisture, MRD, and RMSE values of the 23 sites according to the (a) total, (b) summer, and (c) winter periods in the Korean peninsula.

the summer and winter periods, respectively. The K17 (Imsil) site, which has the lowest MRD value (2.4\%), was the representative site during the summer, and the $\mathrm{K} 7$ (Gimhae) site, which had a MRD value of $2.7 \%$, was the representative site during the winter.

The temporal variations in soil moisture content at the $\mathrm{K} 7$ and $\mathrm{K} 17$ sites from the mean soil moisture at the 23 sites are shown in Fig. 8. This figure shows that the temporal soil moisture content patterns are somewhat different between the K7 and K17 sites. During the summer period the soil moisture values at the K17 site were generally consistent with the mean soil moisture at the 23 sites. However, the soil moisture values at the $\mathrm{K} 7$ site, which is the representa- tive site during the winter period, fluctuated more sharply than the mean soil moisture during this period. During the winter season the temporal soil moisture pattern at the K17 site corresponded to the mean soil moisture patterns (MRD: $2.8 \%$ ), as opposed to the soil moisture pattern at the K7 site (MRD: 12.7\%). Even the K17 pattern appeared to have a larger temporal variation than the $\mathrm{K} 7$ site. This means that representative sites can differ from each other according to the seasonal conditions. Furthermore, this result could imply that the soil moisture temporal stability is determined by climate characteristics (i.e., the Asian monsoon season) rather than soil types, considering that two representative sites do not have dominant soil types, such as loam or sandy 


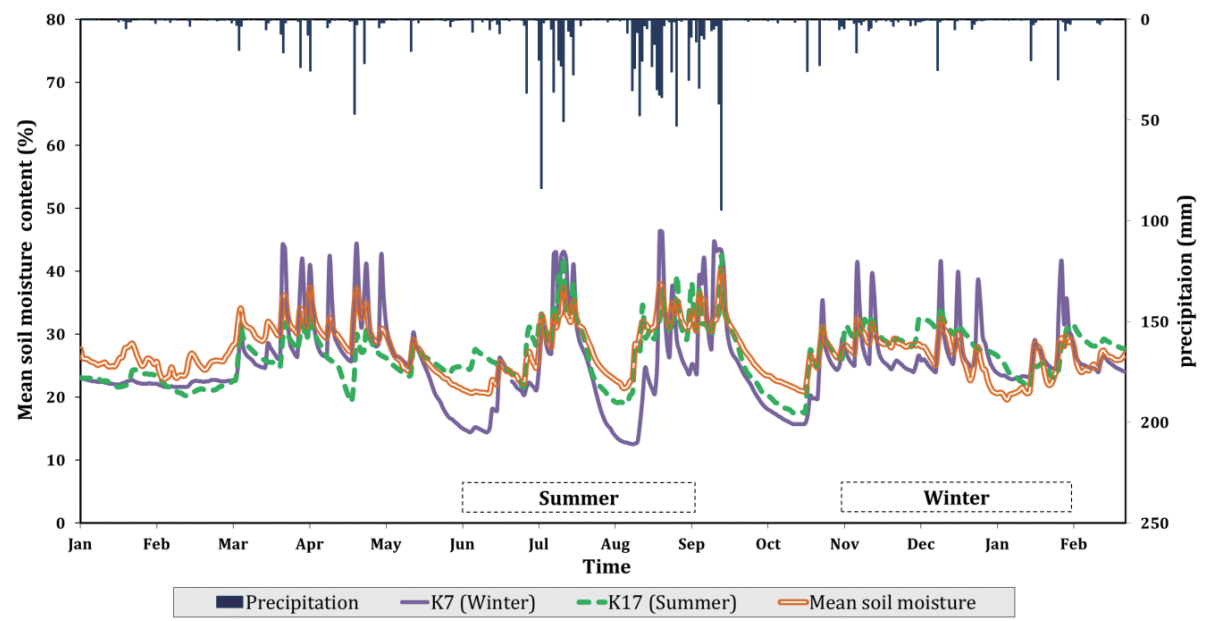

Fig. 8. Time series for the precipitation, mean soil moisture, and representative soil moisture contents of the summer (K17, Imsil) and winter (K7, Gimhae) seasons from 1 January 2012 to 28 February 2013. (Color online only)

loam (K7: Silty clay loam, K17: Silt loam). This result was supported by previous studies that showed spatial representative sites in a regional scale were dominantly controlled by the seasonal characteristics and climate conditions (Martinez et al. 2013; Cho and Choi 2014), while representative sites at field scale should reflect the average topography features (Jacobs et al. 2004; Choi and Jacobs 2007; Brocca et al. 2009). Further studies are needed to understand soil moisture variability more clearly under the various regions in different seasonal/climate conditions.

\section{SUMMARY AND CONCLUSIONS}

This study focused on comparing the seasonal differences in soil moisture distribution and verifying the correlations between soil moisture and meteorological variables, as a function of the season, and investigated how these factors influenced the land surface hydrological cycle in the Korean Peninsula. Soil moisture had a positive relationship with precipitation, air temperature and ground temperature, but the opposite relationship was observed with insolation (i.e., a negative relationship). Soil moisture was affected more significantly by ground temperature than it was by air temperature. The correlations between the ground (air) temperature and soil moisture showed opposite relationships during the summer (June to August) and winter (November to January) seasons. We also estimated the temporal and spatial variations by analyzing the time stability at 23 sites in the Korean peninsula. The K17 (Imsil) and K7 (Gimhae) sites were representative sites during the summer and winter seasons, respectively. Importantly, the representative sites, which possessed time stability, could be altered according to the seasonal conditions of the study area. This study was conducted in the Korean peninsula which has a regional spatial scale. Further research should be conducted in various regions with different meteorological/climate conditions. Our results may be useful for further research regarding climate-meteorological effects on soil moisture patterns as well as in agricultural applications.

Acknowledgements This work was supported by the National Research Foundation of Korea (NRF) grant funded by the Korea government (MSIP) (NRF-2016R1A2B4008312). The authors wish to thank the Rural Development Administration in Korea (http://rda.go.kr) for providing the soil moisture contents and meteorological datasets. We also thank two anonymous reviewers and the Editor for helpful comments and suggestions.

\section{REFERENCES}

Bosch, D. D., V. Lakshmi, T. J. Jackson, M. Choi, and J. M. Jacobs, 2006: Large scale measurements of soil moisture for validation of remotely sensed data: Georgia soil moisture experiment of 2003. J. Hydrol., 323, 120-137, doi: 10.1016/j.jhydrol.2005.08.024. [Link]

Brocca, L., R. Morbidelli, F. Melone, and T. Moramarco, 2007: Soil moisture spatial variability in experimental areas of central Italy. J. Hydrol., 333, 356-373, doi: 10.1016/j.jhydrol.2006.09.004. [Link]

Brocca, L., F. Melone, T. Moramarco, and R. Morbidelli, 2009: Soil moisture temporal stability over experimental areas in Central Italy. Geoderma, 148, 364-374, doi: 10.1016/j.geoderma.2008.11.004. [Link]

Castelli, F., D. Entekhabi, and E. Caporali, 1999: Estimation of surface heat flux and an index of soil moisture using adjoint-state surface energy balance. Water Resour.Res., 35, 3115-3125, doi: 10.1029/1999WR900140. [Link]

Cho, E. and M. Choi, 2014: Regional scale spatio-temporal variability of soil moisture and its relationship 
with meteorological factors over the Korean peninsula. J. Hydrol., 516, 317-329, doi: 10.1016/j.jhydrol.2013.12.053. [Link]

Choi, M. and J. M. Jacobs, 2007: Soil moisture variability of root zone profiles within SMEX02 remote sensing footprints. Adv. Water Resour., 30, 883-896, doi: 10.1016/j.advwatres.2006.07.007. [Link]

Douville, H., 2003: Assessing the influence of soil moisture on seasonal climate variability with AGCMs. J. Hydrometeorol., 4, 1044-1066, doi: 10.1175/1525-7541(2003)004<1044:ATIOSM>2.0.CO;2. [Link]

Entekhabi, D., I. Rodriguez-Iturbe, and F. Castelli, 1996: Mutual interaction of soil moisture state and atmospheric processes. J. Hydrol., 184, 3-17, doi: 10.1016/00221694(95)02965-6. [Link]

Entin, J. K., A. Robock, K. Y. Vinnikov, S. E. Hollinger, S. Liu, and A. Namkhai, 2000: Temporal and spatial scales of observed soil moisture variations in the extratropics. J. Geophys. Res., 105, 11865-11877, doi: 10.1029/2000JD900051. [Link]

Famiglietti, J. S. and E. F. Wood, 1994: Multiscale modeling of spatially variable water and energy balance processes. Water Resour. Res., 30, 3061-3078, doi: 10.1029/94WR01498. [Link]

Famiglietti, J. S., J. A. Devereaux, C. A. Laymon, T. Tsegaye, P. R. Houser, T. J. Jackson, S. T. Graham, M. Rodell, and P. J. van Oevelen, 1999: Ground-based investigation of soil moisture variability within remote sensing footprints during the Southern Great Plains 1997 (SGP97) Hydrology Experiment. Water Resour. Res., 35, 18391851, doi: 10.1029/1999WR900047. [Link]

Famiglietti, J. S., D. Ryu, A. A. Berg, M. Rodell, and T. J. Jackson, 2008: Field observations of soil moisture variability across scales. Water Resour. Res., 44, W01423, doi: 10.1029/2006WR005804. [Link]

Gong, D. Y. and C. H. Ho, 2002: The Siberian High and climate change over middle to high latitude Asia. Theor. Appl. Climatol., 72, 1-9, doi: 10.1007/s007040200008. [Link]

Hinkel, K. M., F. Paetzold, F. E. Nelson, and J. G. Bockheim, 2001: Patterns of soil temperature and moisture in the active layer and upper permafrost at Barrow, Alaska: 1993-1999. Global Planet. Change, 29, 293309, doi: 10.1016/S0921-8181(01)00096-0. [Link]

Jacobs, J. M., B. P. Mohanty, E. C. Hsu, and D. Miller, 2004: SMEX02: field scale variability, time stability and similarity of soil moisture. Remote Sens. Environ., 92, 436-446, doi: 10.1016/j.rse.2004.02.017. [Link]

Jin, M. S. and T. Mullens, 2014: A study of the relations between soil moisture, soil temperatures and surface temperatures using ARM observations and offline CLM4 simulations. Climate, 2, 279-295, doi: 10.3390/ cli2040279. [Link]

Jones, S. B., J. M. Wraith, and D. Or, 2002: Time domain reflectometry measurement principles and applications. Hydrol. Process., 16, 141-153, doi: 10.1002/hyp.513. [Link]

Lakshmi, V., T. J. Jackson, and D. Zehrfuhs, 2003: Soil moisture-temperature relationships: Results from two field experiments. Hydrol. Process., 17, 3041-3057, doi: 10.1002/hyp.1275. [Link]

Lee, Y. H., J. Kim, and J. Hong, 2008: The simulation of water vapor and carbon dioxide fluxes over a rice paddy field by modified Soil-Plant-Atmosphere Model (mSPA). Asia-Pac. J. Atmos. Sci., 44, 69-83.

Martinez, G., Y. A. Pachepsky, H. Vereecken, H. Hardelauf, M. Herbst, and K. Vanderlinden, 2013: Modeling local control effects on the temporal stability of soil water content. J. Hydrol., 481, 106-118, doi: 10.1016/j. jhydrol.2012.12.024. [Link]

Min, Y. M., V. N. Kryjov, K. H. An, S. N. Hameed, S. J. Sohn, W. J. Lee, and J. H. Oh, 2011: Evaluation of the weather generator CLIGEN with daily precipitation characteristics in Korea. Asia-Pac. J. Atmos. Sci., 47, 255-263, doi: 10.1007/s13143-011-0014-y. [Link]

Owe, M., E. B. Jones, and T. J. Schmugge, 1982: Soil moisture variation patterns observed in Hand County, South Dakota. J. Am. Water Resour. Assoc., 18, 949-954, doi: 10.1111/j.1752-1688.1982.tb00100.x. [Link]

Rodriguez-Iturbe, I., 2000: Ecohydrology: A hydrologic perspective of climate-soil-vegetation dynamics. Water Resour. Res., 36, 3-9, doi: 10.1029/1999WR900210. [Link]

Rosenbaum, U., H. R. Bogena, M. Herbst, J. A. Huisman, T. J. Peterson, A. Weuthen, A. W. Western, and H. Vereecken, 2012: Seasonal and event dynamics of spatial soil moisture patterns at the small catchment scale. Water Resour. Res., 48, W10544, doi: 10.1029/2011WR011518. [Link]

Ryu, D. and J. S. Famiglietti, 2005: Characterization of footprint-scale surface soil moisture variability using Gaussian and beta distribution functions during the Southern Great Plains 1997 (SGP97) hydrology experiment. Water Resour. Res., 41, W12433, doi: 10.1029/2004WR003835. [Link]

Seneviratne, S. I., T. Corti, E. L. Davin, M. Hirschi, E. B. Jaeger, I. Lehner, B. Orlowsky, and A. J. Teuling, 2010: Investigating soil moisture-climate interactions in a changing climate: A review. Earth-Sci. Rev., 99, 125-161, doi: 10.1016/j.earscirev.2010.02.004. [Link]

Sur, C., Y. Jung, and M. Choi, 2013: Temporal stability and variability of field scale soil moisture on mountainous hillslopes in Northeast Asia. Geoderma, 207-208, 234243, doi: 10.1016/j.geoderma.2013.05.007. [Link]

Topp, G. C., J. L. Davis, and A. P. Annan, 1980: Electromagnetic determination of soil water content: Measurements in coaxial transmission lines. Water Resour. Res., 16, 574-582, doi: 10.1029/WR016i003p00574. [Link] 
Tuttle, S. and G. Salvucci, 2016: Empirical evidence of contrasting soil moisture-precipitation feedbacks across the United States. Science, 352, 825-828, doi: 10.1126/ science.aaa7185. [Link]

Van den Hurk, B., F. Doblas-Reyes, G. Balsamo, R. D. Koster, S. I. Seneviratne, and H. Camargo, 2012: Soil moisture effects on seasonal temperature and precipitation forecast scores in Europe. Climate Dyn., 38, 349362, doi: 10.1007/s00382-010-0956-2. [Link]
Yang, M., T. Yao, X. Gou, T. Koike, and Y. He, 2003: The soil moisture distribution, thawing-freezing processes and their effects on the seasonal transition on the Qinghai-Xizang (Tibetan) plateau. J. Asian Earth Sci., 21, 457-465, doi: 10.1016/S1367-9120(02)00069-X. [Link] Yang, S. and K. M. Lau, 1998: Influences of sea surface temperature and ground wetness on Asian summer monsoon. J. Climate, 11, 3230-3246, doi: 10.1175/15200442(1998)011<3230:IOSSTA>2.0.CO;2. [Link] 